Portland State University

PDXScholar

2018

\title{
Biodiversity Gains? The Debate on Changes in Local- vs Global-Scale Species Richness
}

\author{
Richard B. Primack \\ Boston University \\ Abraham J. Miller-Rushing \\ US National Park Service \\ Richard T. Corlett \\ Chinese Academy of Sciences, Menglun, Yunnan, China \\ Vincent Devictor \\ CNRS-Univerité Montpellier \\ David Johns \\ Portland State University, johnsd@pdx.edu
}

See next page for additional authors

Follow this and additional works at: https://pdxscholar.library.pdx.edu/polisci_fac

Part of the Political Science Commons

Let us know how access to this document benefits you.

\section{Citation Details}

Primack, R. B., Miller-Rushing, A. J., Corlett, R. T., Devictor, V., Johns, D. M., Loyola, R., ... \& Pejchar, L. (2018). Biodiversity gains? The debate on changes in local-vs global-scale species richness.

This Article is brought to you for free and open access. It has been accepted for inclusion in Political Science Faculty Publications and Presentations by an authorized administrator of PDXScholar. Please contact us if we can make this document more accessible: pdxscholar@pdx.edu. 


\section{Authors}

Richard B. Primack, Abraham J. Miller-Rushing, Richard T. Corlett, Vincent Devictor, David Johns, Rafael Loyola, Bea Hass, Robin J. Pakeman, and Liba Pejchar 
Editorial

\section{Biodiversity gains? The debate on changes in local- vs global-scale species richness}

Do changes in biodiversity at local scales reflect the declines seen at global scales? This debate dates back at least 15 years (Sax and Gaines, 2003), but has recently been revived by several authors (e.g., Gonzalez et al., 2016; Vellend et al., 2017). The heated exchanges on this issue are reminiscent of earlier debates on the nature of the field, and if "conservation biology," which originated as a crisis discipline focused on protecting biodiversity (Soulé, 1985), should transition to "conservation science," which attempts to maximize the preservation of biodiversity together with human well-being (Kareiva and Marvier, 2012). Why would a debate that largely centers on data interpretation-as the debate about changes in local-scale biodiversity does-become so intense?

It is probably because this debate involves the primary rationale for the modern conservation movement-that human activities are causing major declines in biodiversity around the world (Ripple et al., 2017), and that these declines are bad from the perspectives of science, ethics and values, ecosystem services, and human well-being (Pascual et al., 2017). This particular debate, though, addresses primarily one aspect of recent trends in biodiversity: changes in species richness at local scales in relatively intact ecological communities. These trends do not necessarily reflect changes in other components of biodiversity (e.g., functional, phylogenetic, genetic, or phenotypic), changes in biodiversity in heavily altered landscapes (e.g., agricultural fields or urbanized areas), or changes in global species richness-at which scale biodiversity is clearly declining (Ceballos et al., 2015; Ceballos et al., 2017; Pimm et al., 2014).

Assessing local changes in species richness provides insights that are ecologically important and conservation-relevant, but these studies are often hampered by a shortage of baseline data and the absence of long-term monitoring. Researchers therefore must often rely on data from studies that were designed to address other research questions, such as how plant communities recover from disturbance (Cardinale et al., 2017-in this issue). These studies and data are also not distributed around the world in an ideal way to assess global patterns of local changes in species richness (Gonzalez et al., 2016). Given these constraints, research groups have taken different approaches to explore the topic: some groups have compared species richness in human-disturbed and reference sites (e.g., Moreno-Mateos et al., 2017), and some have analyzed data from sites that had been resurveyed over time (Dornelas et al., 2014; Vellend et al., 2013).

Together results suggest that dramatic human disturbances, such as agricultural expansion and urbanization, result in significant declines in local species richness, but that in areas where ecosystems are still relatively intact, such as old fields and second growth forests, species richness tends to remain relatively constant or even increase over time (Vellend et al., 2017). Thus, if you go to a specific place-such as New Zealand, Hawaii, or Massachusetts - the forests, wetlands, and grasslands might now have fewer native species, but the same number or more species overall than they did in the past. How is this possible? This stability in local-scale biodiversity usually results from the presence of non-native species numerically offsetting losses of native species (Vellend et al., 2017)—i.e., 30 native species might disappear from a location, but 30, 40, or more non-native species might arrive and become established-although the evidence for the generality of this pattern is questioned (Cardinale et al., 2017-in this issue). This debate even spilled over into public attention when Pyron (2017) asserted in the Washington Post that human-caused extinction of species is not a problem, because if the 50 native reptiles of South Florida went extinct they would be replaced by the 90 non-native reptiles are now living there.

Some conservation researchers have reacted strongly to these findings. They have argued that some of the meta-analyses (e.g., Dornelas et al., 2014; Vellend et al., 2013) are flawed because the underlying data: (1) are not spatially representative of biodiversity around the globe (they are biased toward North America and Europe), (2) are not representative of the primary drivers of biodiversity change (they omit sites that had been converted to agriculture or urban development), (3) combine data from sites that had recently been perturbed and are likely losing species with data from sites that were recovering from perturbations, and (4) rely on time series that lack historical baselines, making it difficult to accurately characterize biodiversity change (summarized in Cardinale et al., 2017-in this issue).

These points are sound, but the criticisms do not discount the value of the analyses that Vellend et al. (2013), Dornelas et al. (2014), and others have done. Their analyses are reasonable and convincing given the available data, and the weaknesses, which the authors acknowledge, are difficult or impossible to avoid. Moreover, several subsequent studies in different ecological communities have found similar patterns of high species turnover and relatively steady or increasing species richness at local scales (Barnagaud et al., 2017; Dunic et al., 2017; Elahi et al., 2015; Gotelli et al., 2017; Jones et al., 2017). Conservation researchers, practitioners, and policymakers should recognize the limitations of the results, but should consider their implications as the research continues, and adjust their goals and actions accordingly (admittedly easier said than done) (Fleischman and Briske, 2016; Knight et al., 2008). In reading papers on both sides of this controversy, we at Biological Conservation want to highlight three key points 


\section{that emerge:}

First, none of the research discussed here questions the global decline in biodiversity. Throughout the world species have gone extinct because of human activity, a large percentage of species are threatened with extinction, and numerous local populations of species have been extirpated (Barnosky et al., 2011). Some authors have considered whether speciation rates may be increasing because of the novel situations people have created (Sax and Gaines, 2003; Thomas, 2017), but rates of extinction are currently far outpacing speciation, driven by human activities and the resulting changes to the global environment (Ceballos et al., 2015; Pimm et al., 2014). Additionally, rates of speciation are most likely to increase for organisms that hybridize and those with short generation times (e.g., bacteria, insects, and annual plants), not for phylogenetically distinct species and longer-lived groups most vulnerable to extinction (Schluter and Pennell, 2017; Thomas, 2015; Vellend et al., 2007).

Second, this research suggests that while native biodiversity may be declining at all scales, local species richness (i.e., alpha diversity) is not declining in many places because the loss of native species is balanced by the establishment of new native and, especially, non-native species (Dornelas et al., 2014; Dunic et al., 2017; Hillebrand et al., 2017). As the authors note, these observations are consistent with biotic homogenization, in which nearby local sites become more similar (i.e. reducing beta diversity) as particular species spread and colonize sites (Olden, 2006). Localscale studies tell us little about changes in species richness at regional or larger scales (i.e., gamma diversity, or the regional species pool). All things being equal, we would expect regional diversity of native species to decline if local species richness is stable while sites become more homogenous. Plant species richness is certainly increasing in many regions, such as New Zealand or Hawaii, where the arrival of non-native species is outpacing the loss of native species (McGill et al., 2015), and some non-native species are directly displacing native species.

Third, the research highlights the problem of relying too heavily on simple measures of biodiversity, particularly local measures of species richness, as rationales for investing in conservation and for taking particular conservation actions at local scales (Hillebrand et al., 2017). Local-scale conservation serves many purposes beyond preserving species richness, including preserving ecological processes (e.g., species interactions, nutrient cycles), other components of biodiversity (e.g., functional, phylogenetic, genetic, or phenotypic), healthy populations, and intrinsic and historical values (Pearson, 2016). Additionally, local conservation (i.e., most conservation) contributes to the preservation of biodiversity at larger scales (beta and gamma diversity). The finding that species richness is stable or increasing in many locations is not a reason to stop local-scale conservation actions.

These findings do, however, raise several questions related to how we prioritize conservation goals and actions at local scales, such as for protected areas, ecosystem restoration, and invasive species management. The questions necessarily intertwine science and values (Pearson, 2016). For example, should managers work to preserve native species and communities, or should they work to maintain ecosystem processes and services by managing species assemblages, regardless of whether the species are native or non-native (Belnap et al., 2012; Cardinale, 2012)? Can newly arrived species sometimes "replace" ecosystem functions and services provided by lost native species (Foster and Robinson, 2007; Pejchar, 2015)? If so, is it desirable, right, and legitimate, and is it really possible to predict when functions and services might be successfully replaced (Pakeman and Lewis, 2018)? How should managers work to maintain viable populations of species at local scales, when we expect their abundance and ranges to shift in response to globally changing conditions? The population sizes of many species, including common species, are declining (not just shifting ranges), and these declines may not show up in species richness data (Ceballos et al., 2017). Should managers embrace novel ecosystems as changes in species composition become ubiquitous and largely unavoidable (Hillebrand et al., 2017; Hobbs et al., 2014)? In a rapidly changing environment, is nativeness an important component of ecological integrity, which many conservation organizations use as a key management goal? When should managers resist change in ecosystems? And how should managers weight local- and global-scale patterns and processes when setting their conservation goals and priorities?

Even though the debate around global changes in local-scale species richness centers on data, analyses, and interpretation, it also touches on conservation values and can inform how we do conservation on the ground. In conservation research, this mixing of values and science is unavoidable, given that the goals of conservation are largely derived from human values-e.g., that there is intrinsic value in the natural diversity of organisms and that it is important to avoid human-caused extinctions. Unfortunately, researchers are sometimes reluctant to write papers with findings that appear to run counter to the values and dogma of conservation, and other researchers are quick to criticize when such findings are published. The repercussions of publishing results that question conservation dogma are real—social media commentators, members of the press, and others (sometimes even scientists) may misrepresent conservation research when they question whether biodiversity is really declining, whether humans are causing mass extinctions, and whether we should be concerned about how humans are changing the world (Ladle et al., 2005; Pyron, 2017). Conservation scientists are understandably concerned that misrepresentations could translate to reduced support for conservation research and practice. Apparently, one reviewer used this concern as justification for recommending against publishing the work of Vellend and colleagues in a prominent journal (Kloor, 2017). Clearly, though, we should not shy away from honest discussions that advance science, from publishing sound science (whether it represents "good" or "bad" news for currently accepted practices in conservation), or from debating and addressing core questions of the field.

We at Biological Conservation believe research and discussions that challenge the central tenets of conservation biology should be encouraged. Indeed, rich discussions are already happening. During these discussions, as conservation researchers and practitioners, we should clearly identify the science and the value-based components of our reasoning. We should not be unfairly critical of data and analyses because the results contradict our expectations or values, and we should be careful to communicate clearly and fairly (e.g., making clear distinctions between local vs. global trends). We should also try to make the context and limitations of our results clear when communicating with the media, the public, and government officials; but that should not stop us from doing and publishing good science and pushing the field forward, even if it means challenging dogma. We appreciate the frankness and honesty that Vellend (2017) and others (e.g., Cardinale et al., 2017-in this issue) are using to present the cases for their science. These types of debates help us identify and address key questions and problems, and help us generate the shared understanding necessary to advance the field of conservation biology and to achieve conservation goals on the ground.

\section{Acknowledgements}

We thank Bradley Cardinale, Nick Gotelli, Michel Loreau, Kathryn Miller, and Mark Vellend for their comments and discussions related to this editorial. The findings and conclusions in this paper are those of the authors and do not necessarily represent the views of the funding agencies or the Department of Interior or the US Government. 


\section{References}

Barnagaud, J.Y., Gauzere, P., Zuckerberg, B., Prince, K., Svenning, J.C., 2017. Temporal changes in bird functional diversity across the United States. Oecologia 185, 737-748.

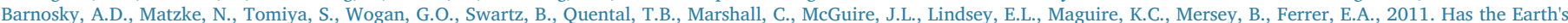
sixth mass extinction already arrived? Nature 471, 51-57.

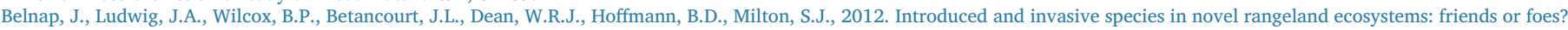
Rangel. Ecol. Manag. 65, 569-578.

Cardinale, B., 2012. Impacts of biodiversity loss. Science 336, 552-553.

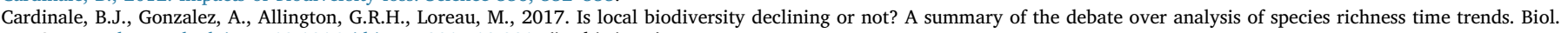
Conserv. http://dx.doi.org/10.1016/j.biocon.2017.12.021. (in this issue).

Ceballos, G., Ehrlich, P.R., Barnosky, A.D., García, A., Pringle, R.M., Palmer, T.M., 2015. Accelerated modern human-induced species losses: entering the sixth mass extinction. Sci. Adv. 1.

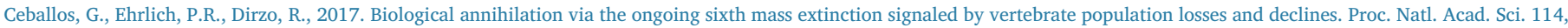
E6089-E6096.

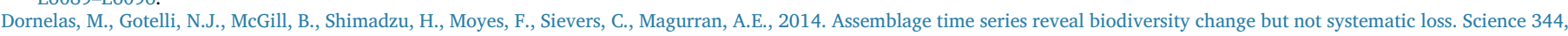
296-299.

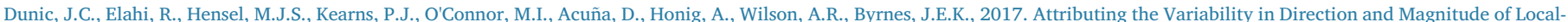
Scale Marine Biodiversity Change to Human Activities. (bioRxiv).

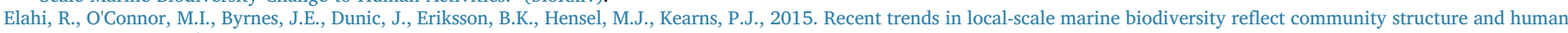
impacts. Curr. Biol. 25, 1938-1943.

Fleischman, F., Briske, D., 2016. Professional ecological knowledge: an unrecognized knowledge domain within natural resource management. Ecol. Soc. 21.

Foster, J.T., Robinson, S.K., 2007. Introduced birds and the fate of Hawaiian rainforests. Conserv. Biol. 21, 1248-1257.

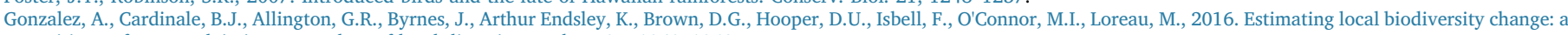
critique of papers claiming no net loss of local diversity. Ecology 97, 1949-1960.

Gotelli, N.J., Shimadzu, H., Dornelas, M., McGill, B., Moyes, F., Magurran, A.E., 2017. Community-level regulation of temporal trends in biodiversity. Sci. Adv. 3 , e1700315.

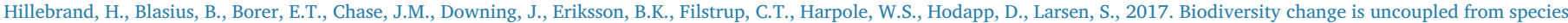
richness trends: consequences for conservation and monitoring. J. Appl. Ecol. 00, 1-16.

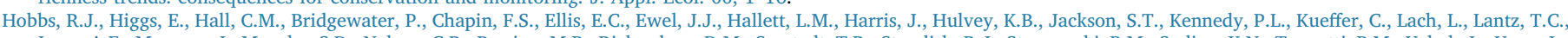
Lugo, A.E., Mascaro, J., Murphy, S.D., Nelson, C.R., Perring, M.P., Richardson, D.M., Seastedt, T.R., Standish, R.J., Starzomski, B.M., Suding, K.N., Tognetti, P.M., Yakob, L., Yung, L., 2014. Managing the whole landscape: historical, hybrid, and novel ecosystems. Front. Ecol. Environ. 12, 557-564.

Jones, S.K., Ripplinger, J., Collins, S.L., 2017. Species reordering, not changes in richness, drives long-term dynamics in grassland communities. Ecol. Lett. 20, 1556-1565.

Kareiva, P., Marvier, M., 2012. What is conservation science? Bioscience 62, 962-969.

Kloor, K., 2017. The science police. Issues Sci. Technol. 33. http://issues.org/33-34/the-science-police/.

Knight, A.T., Cowling, R.M., Rouget, M., Balmford, A., Lombard, A.T., Campbell, B.M., 2008. Knowing but not doing: selecting priority conservation areas and the research-implementation gap. Conserv. Biol. 22, 610-617.

Ladle, R.J., Jepson, P., Whittaker, R.J., 2005. Scientists and the media: the struggle for legitimacy in climate change and conservation science. Interdiscip. Sci. Rev. 30, 231-240.

McGill, B.J., Dornelas, M., Gotelli, N.J., Magurran, A.E., 2015. Fifteen forms of biodiversity trend in the Anthropocene. Trends Ecol. Evol. 30 , $104-113$.

Moreno-Mateos, D., Barbier, E.B., Jones, P.C., Jones, H.P., Aronson, J., López-López, J.A., McCrackin, M.L., Meli, P., Montoya, D., Benayas, J.M.R., 2017. Anthropogenic ecosystem disturbance and the recovery debt. Nat. Commun. 8, 14163.

Olden, J.D., 2006. Biotic homogenization: a new research agenda for conservation biogeography. J. Biogeogr. 33, $2027-2039$.

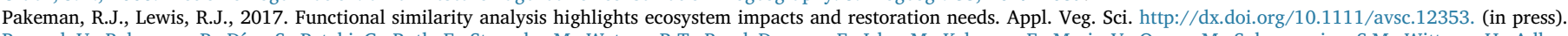

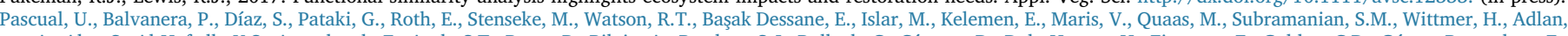
A., Ahn, S., Al-Hafedh, Y.S., Amankwah, E., Asah, S.T., Berry, P., Bilgin, A., Breslow, S.J., Bullock, C., Cáceres, D., Daly-Hassen, H., Figueroa, E., Golden, C.D., Gómez-Baggethun, E., González-Jiménez, D., Houdet, J., Keune, H., Kumar, R., Ma, K., May, P.H., Mead, A., O'Farrell, P., Pandit, R., Pengue, W., Pichis-Madruga, R., Popa, F., Preston, S., Pacheco-Balanza, D., Saarikoski, H., Strassburg, B.B., van den Belt, M., Verma, M., Wickson, F., Yagi, N., 2017. Valuing nature's contributions to people: the IPBES approach. Curr. Opin. Environ. Sustain. 26-27, 7-16.

Pearson, R.G., 2016. Reasons to conserve nature. Trends Ecol. Evol. 31, 366-371.

Pejchar, L., 2015. Introduced birds incompletely replace seed dispersal by a native frugivore. AoB Plants 7, plv072.

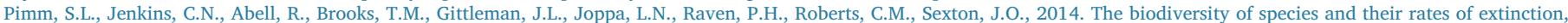
distribution, and protection. Science 344, 1246752.

Pyron, R.A., 2017. We Don't Need to Save Endangered Species. Extinction Is Part of Evolution. In The Washington Post, Washington, DC.

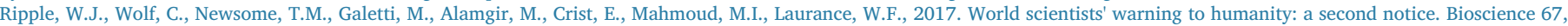
$1026-1028$.

Sax, D.F., Gaines, S.D., 2003. Species diversity: from global decreases to local increases. Trends Ecol. Evol. 18, 561-566.

Schluter, D., Pennell, M.W., 2017. Speciation gradients and the distribution of biodiversity. Nature 546, 48-55.

Soulé, M.E., 1985. What is conservation biology? Bioscience 35, 727-734.

Thomas, C.D., 2015. Rapid acceleration of plant speciation during the Anthropocene. Trends Ecol. Evol. 30, 448-455.

Thomas, C.D. 2017. Inheritors of the Earth: How Nature Is Thriving in an Age of Extinction. PublicAffairs.

Vellend, M., 2017. The biodiversity conservation paradox. Am. Sci. 105, 94-101.

Vellend, M., Baeten, L., Becker-Scarpitta, A., Boucher-Lalonde, V., McCune, J.L., Messier, J., Myers-Smith, I.H., Sax, D.F., 2017. Plant biodiversity change across scales during the Anthropocene. Annu. Rev. Plant Biol. 68, 563-586.

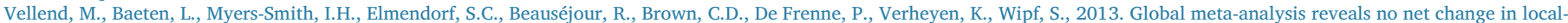
scale plant biodiversity over time. Proc. Natl. Acad. Sci. 110, 19456-19459.

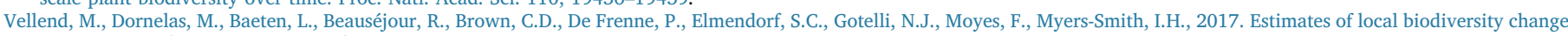
over time stand up to scrutiny. Ecology 98, 583-590.

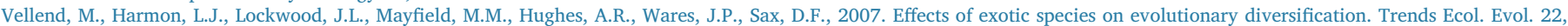
481-488.

Richard B. Primack $^{\mathrm{a}, *}$, Abraham J. Miller-Rushing ${ }^{\mathrm{b}}$, Richard T. Corlett ${ }^{\mathrm{c}}$, Vincent Devictor ${ }^{\mathrm{d}}$, David M. Johns ${ }^{\mathrm{e}}$, Rafael Loyola ${ }^{\mathrm{f}, \mathrm{g}}$, Bea Maas ${ }^{\mathrm{h}}$, Robin J. Pakeman ${ }^{\mathrm{i}}$, Liba Pejchar

${ }^{a}$ Department of Biology, Boston University, 5 Cummington Mall, Boston, MA 02215, USA

${ }^{\mathrm{b}}$ US National Park Service, Acadia National Park and Schoodic Education and Research Center, Bar Harbor, ME 04609, USA ${ }^{\mathrm{c}}$ Center for Integrative Conservation, Xishuangbanna Tropical Botanical Garden, Chinese Academy of Sciences, Menglun, Yunnan 666303, China

d Institut des Sciences de l'Evolution de Montpellier, CNRS-Univerité Montpellier, 34095 Montpellier, France

e School of Government, Portland State University, Portland, OR 97207, USA

${ }^{\mathrm{f}}$ Laboratório de Biogeografia da Conservação, Universidade Federal de Goiás, Goiânia, GO, Brazil

${ }^{g}$ Centro Nacional de Conservação da Flora, Instituto de Pesquisas Jardim Botânico do Rio de Janeiro, Rio de Janeiro, RJ, Brazil

${ }^{\mathrm{h}}$ Department of Botany and Biodiversity Research, Division of Conservation Biology, Vegetation Ecology and Landscape Ecology, University of Vienna, Rennweg, 141030 Vienna, Austria

${ }^{i}$ The James Hutton Institute, Craigiebuckler, Aberdeen AB15 8QH, UK ${ }^{\mathbf{j}}$ Department of Fish, Wildlife and Conservation Biology, Colorado State University, 1474 Campus Delivery, Fort Collins, CO 80523, USA E-mail address: primack@bu.edu

* Corresponding author. 